\title{
Exclusive goods and formal-sector employment
}

Föllmi, Reto ; Zweimüller, Josef

\begin{abstract}
We explore how the underemployment problem of less-developed economies is related to income inequality. Consumers have nonhomothetic preferences over differentiated products of formal-sector goods and thus inequality affects the composition of aggregate demand via the price-setting behavior of firms. We find that high inequality divides the formal sector into mass producers and exclusive producers (which serve only the rich); high inequality generates an equilibrium where many workers are crowded into the informal economy; and an increase in subsistence productivity raises the unskilled workers' wages and boosts employment due to the higher purchasing power of poorer households.
\end{abstract}

DOI: https://doi.org/10.1257/mac.3.1.242

Posted at the Zurich Open Repository and Archive, University of Zurich ZORA URL: https://doi.org/10.5167/uzh-57336

Journal Article

Published Version

Originally published at:

Föllmi, Reto; Zweimüller, Josef (2011). Exclusive goods and formal-sector employment. American Economic Journal: Macroeconomics, 3(1):242-272.

DOI: https://doi.org/10.1257/mac.3.1.242 


\title{
Exclusive Goods and Formal-Sector Employment
}

\author{
By Reto Foellmi And Josef ZweImÜlleR*
}

\begin{abstract}
We explore how the underemployment problem of less-developed economies is related to income inequality. Consumers have nonhomothetic preferences over differentiated products of formal-sector goods and thus inequality affects the composition of aggregate demand via the price-setting behavior of firms. We find that high inequality divides the formal sector into mass producers and exclusive producers (which serve only the rich); high inequality generates an equilibrium where many workers are crowded into the informal economy; and an increase in subsistence productivity raises the unskilled workers' wages and boosts employment due to the higher purchasing power of poorer households. (JEL D31, D43, E24, E26, J24)
\end{abstract}

$\mathrm{n}$ old idea in economics holds that a more egalitarian income distribution may be beneficial for aggregate employment through its effect on the composition of consumer demand. High purchasing power in the hands of the lower classes generates large markets that foster industrialization and the emergence of a massconsumption society. In contrast, high inequality may generate a large reserve army of labor stuck in agriculture or marginalized in urban areas. As a result, high ex ante inequality in the distribution of productive resources can be an obstacle to economic development.

In this paper, we present a dual economy model with a modern (formal) sector and a subsistence (informal) sector in which income inequality becomes a crucial determinant of modern-sector employment. We focus on a novel mechanism largely neglected by the previous literature: the impact of income inequality on prices and mark-ups set by modern firms. The basic idea is that an unequal income distribution may induce some firms to set high prices and mark-ups and sell their products exclusively to rich consumers. Other firms set low prices, making their product affordable to the poor. We will call the latter firms "mass producers" and the former

\footnotetext{
* Foellmi: University of Berne and CEPR, Department of Economics, Schanzeneckstrasse 1, CH-3001 Berne (e-mail: reto.foellmi@vwi.unibe.ch); Zweimüller: University of Zurich, Bluemlisalpstrasse 10, CH-8006 Zürich and CEPR, Institute for Empirical Research in Economics (e-mail: zweim @iew.unizh.ch). Zweimüller is also associated with CESifo and IZA. We thank George-Marios Angeletos, Armin Falk, Josef Falkinger, Marco Leonardi, Lars Ljungqvist, Manuel Oechslin, Gilles Saint-Paul, and Tobias Wuergler for valuable discussion. We also thank seminar participants in Toulouse, MIT, Munich, IHS Vienna, Linz, the ESSLE meeting in Ammersee, the ESEM meeting in Stockholm, the SSES meeting in Berne, the IZA meeting on "Structural change and labour markets," Freiburg, Makroökonomischer Ausschuss des Vereins für Socialpolitik, WIIW Vienna, and Trade Union Institute Stockholm. Reto Foellmi acknowledges support from the SNF Research Grant No. PA001-105068.

${ }^{\dagger}$ To comment on this article in the online discussion forum, or to view additional materials, visit the article page at http://www.aeaweb.org/articles.php?doi=10.1257/mac.3.1.242.
} 
firms "exclusive producers" (because they charge prices unaffordable to the poor and "exclude" them from the customer base). Because a more unequal society will generate a higher (lower) fraction of exclusive (mass) producers, and because exclusive (mass) producers hire few (many) workers, a negative impact of inequality on formal-sector employment is established.

Empirical evidence is consistent with such a negative inequality-employment relationship. Alberto Chong and Mark Gradstein (2007) find a robust correlation between income inequality and various measures of informal-sector activity in a cross section of countries and show that this relationship is robust to various measures of informality and/or inequality. J. Barkley Rosser, Marina V. Rosser, and Ehsan Ahmed (2000) use panel data from 16 transition economies and document that increases in inequality are associated with larger shares of output in the informal economy. Diego Winkelried (2005) uses a panel of Mexican metropolitan areas and finds that informal sector activity is positively affected by the Gini coefficient. Moreover, a large middle class (as measured by the third and fourth quintiles of the income distribution) is strongly, negatively associated with the size of the informal sector.

For obvious reasons, our analysis is of particular relevance to developing economies where the formal sector is small, leaving the economy with a reserve army of labor trapped in subsistence. Arguably one of the most important obstacles for the development of a dynamic manufacturing sector is a weak education system and a lack of entrepreneurial talent. An additional major obstacle to entry are high direct or indirect entry costs that may be prohibitive even for promising projects. One important reason is the limited access to credit (see, e.g., Simeon Djankov, Caralee McLiesh, and Andrei Shleifer 2007). Moreover, there is ample evidence that setting up a new business is often associated with extremely high costs (Hernando de Soto 1989; James R. Tybout 2000). Government regulation, high fees and time-consuming procedures can often make it costly to start up a new business (Djankov et al. 2002). Additional entry costs may arise from corruption and bribes to overcome and/or speed up the start-up process of new business (see, e.g., Foellmi and Manuel Oechslin 2007).

To capture such major barriers to entry, high fixed costs and a limited supply of entrepreneurial skills are crucial ingredients of our model. We assume that there are skilled and unskilled workers. Skilled workers are rich and can afford the goods supplied by both mass and exclusive producers. Unskilled workers are poor and can afford only the subset of the goods supplied by mass producers. Moreover, skilled workers decide whether to set up and run a modern firm or to work in production at high wages. In equilibrium, they are fully employed and indifferent between the two activities. Unskilled workers either find employment in the modern sector or are otherwise trapped in subsistence. In equilibrium, the wages of unskilled workers are governed by productivity in subsistence and unskilled workers are indifferent regarding whether they work between working in the formal sector or in subsistence production. ${ }^{1}$

\footnotetext{
${ }^{1}$ The assumption that workers are indifferent between subsistence and formal sector work is made for simplicity. We could think of a factory-premium wage (as in Kevin M. Murphy, Shleifer, and Robert Vishny 1989) or
} 
A situation with exclusive producers and mass producers is hard to generate in the standard monopolistic competition model, where consumers have homothetic preferences and prices and mark-ups are invariant to market size. As a result, our analysis deviates from the standard model by assuming non-homothetic preferences. To generate the above price and employment effect, our specification of preferences features demand functions with decreasing price elasticities. Decreasing price elasticities imply that rich consumers who are able to select a point lower down in the demand curve have a lower price elasticity, allowing firms to charge a higher mark-up. The simplest case that generates such a situation is that of quadratic preferences. Quadratic preferences feature linear individual demand curves (with potentially binding nonnegativity constraints) and provide us with a simple and tractable framework of analysis. Nevertheless, the quadratic specification should be viewed as an example that, as discussed at the end of the paper, extends to more general specifications of preferences.

Understanding the role of non-homothetic preferences for aggregate outcomes is of more general importance. On the one hand, the standard assumption of homothetic preferences is highly unrealistic from an empirical point of view. Previous empirical research on the shape of Engel curves has uniformly rejected the hypothesis of unit income elasticities for all products. ${ }^{2}$ On the other hand, the aggregate implications of non-homothetic preferences are not well understood, as the representative agent paradigm can no longer be applied. This is particularly relevant in the context of developing economies, where income differences between consumers are typically very large. A potentially interesting feature of non-homothetic preferences is variable mark-ups. As a result, incorporating non-homothetic preferences into a general-equilibrium framework highlights interesting interactions between inequality on the one side and mark-ups, real wages, the size distribution of modern firms, and the allocation of employment across sectors on the other side. Such interrelationships, while potentially important in practice, are ruled out by assumption in the standard framework with CES preferences. ${ }^{3}$

Our analysis yields three important results. First, sufficiently high inequality divides the modern sector into mass-consumption firms and exclusive firms. Such an asymmetric equilibrium arises even though all modern firms are assumed to be identical ex ante (i.e., have identical cost and demand curves). In equilibrium, firms are indifferent between selling only to the rich at high prices or selling to both the rich and the poor at lower prices. In other words, there are small markets, where producers take advantage of the rich's high willingness to pay and set prices that the

\footnotetext{
an efficiency wage (as in Partha Dasgupta and Debraj Ray 1987, or Jeremy I. Bulow and Lawrence H. Summers 1986). Adding such assumptions would generate an equilibrium where unskilled workers are strictly better off when employed in the formal sector. Such assumptions would have an impact on the shape of the (effective) labor supply function. Because the main point of our analysis is on how inequality affects the product and labor demand of modern sector firms, the particular shape of the labor supply function is not essential.

${ }^{2}$ For a recent summary of the state of research on Engel-curves, see Arthur Lewbel (2006).

${ }^{3}$ In the second part of their seminal paper, Avinash K. Dixit and Joseph E. Stiglitz (1977) explore the implications of variable elasticities of substitution (VES). However, they abstain from introducing income inequality into their model. Our analysis shows that introducing heterogeneous consumers fundamentally changes the character of the general equilibrium.
} 
poor cannot afford, and there are mass markets, where producers set low prices and take advantage of a large market.

Second, an exogenous increase in inequality is associated with lower labor demand by the modern sector. The effect is driven by the composition of modernsector firms. When inequality is high, there are few mass producers and many exclusive producers. When inequality is low, mass consumption is more prevalent, and the overall level of formal-sector employment is large. The reason is that, with high inequality, both mass producers and exclusive producers set higher prices and markups. As a result, for given wages, the aggregate demand for unskilled labor falls, and the fraction of poor households engaged in subsistence increases. This result holds true regardless of the size of the subsistence sector.

Third, an increase in subsistence productivity boosts wages and employment of unskilled workers. Higher subsistence productivity forces modern firms to pay higher unskilled wages, reducing aggregate inequality. Because of the reasons outlined in the previous paragraph, the extent of mass consumption and hence formal-sector employment increases. Moreover, an increase in subsistence productivity may not only increase the welfare of poor households but may also increase the welfare of the rich. Even though higher unskilled wages decrease the income of wealthy households, the rich benefit due to a larger menu of mass-consumption goods and their lower prices.

There is a small literature studying how the interaction of non-homothetic preferences and income distribution affects the sectoral distribution of output and employment in the context of economic development. Kiminori Matsuyama (2002) studies a model where consumers have non-homothetic preferences and income inequality affects employment in dynamic sectors that generate technical progress via learning-by-doing. He is interested in the dynamic evolution of the economy, whereas our focus is on aggregate employment in a static context. Moreover, firms in the Matsuyama model operate on competitive product markets, whereas in our model firms exert market power and crucially affect employment via price setting. Murphy, Shleifer, and Vishny (1989) study the effect of income inequality on market size and manufacturing employment under non-homothetic preferences. Their focus is on the entry of firms operating with superior technologies. In their model, mark-ups and prices are taken as given. In contrast, our analysis focuses on a situation where entry is prohibited and income distribution effects work via endogenous prices and mark-ups. ${ }^{4}$

Winkelried (2005) presents a model where firms decide whether or not to enter the formal sector. In this decision, the size of the market (which is determined by the distribution of income across households) plays an important role. This is different from the present framework, where all informal-sector workers are trapped in subsistence. Gilles Saint-Paul (2006) studies a monopolistic competition model with non-homothetic preferences and shows that non-homothetic preferences that feature

\footnotetext{
${ }^{4}$ Other papers that incorporate non-homothetic preferences into a general equilibrium framework are Josef Falkinger (1994), Chien-fu Chou and Gabriel Talmain (1996), Chol-Won Li (1996), Oded Galor and Omer Moav (2004), and Foellmi and Josef Zweimüller (2006a) in the context of economic growth and Harry Flam and Elhanan Helpman (1987), Matsuyama (2000), and Devashish Mitra and Vitor Trindade (2005) in the context of international trade.
} 
decreasing price elasticities of demand generate an ambiguous relationship between technical progress and the real wage. While the mechanism in the present paper is similar, Saint-Paul sticks to a representative agent framework and studies the impact of the factor-income distribution in the context of long-run growth. In contrast, our focus is on a developing economy and the interaction between price-setting behavior and income inequality, which allows us to explore the effects of inequality on formal-sector employment. ${ }^{5}$

The paper is organized as follows. In Section I, we present our basic model and derive the households' optimal consumption levels and the monopolists' optimal prices and quantities. Section II characterizes an asymmetric equilibrium. Section III briefly presents the symmetric case. Section IV proofs the existence of equilibria. Section $V$ addresses the question of our primary interest: the relationship between inequality and modern-sector employment. In Section VI, we discuss the robustness of our results with respect to the central assumptions, and Section VII concludes.

\section{A Model of Monopolistic Competition with Quadratic Preferences}

\section{A. Consumers}

There is a population of heterogenous households with total mass 1 . To keep the analysis transparent and simple, we consider a two-class society with $\beta$ rich and $1-\beta$ poor households. Rich households are endowed with skilled labor ("entrepreneurial talent" or "human capital"). Poor households are endowed with unskilled labor. Subscripts $P$ and $R$ refer to poor (unskilled) households and rich (skilled) households. (The terms "unskilled" and "poor" and the terms "skilled" and "rich" will be used synonymously.) The aggregate stocks of skilled and unskilled labor are denoted by $H$ and $L$, respectively. The typical poor household is therefore endowed with $L / \beta$ units of unskilled labor and the typical rich household is endowed with $H /(1-\beta)$ units of skilled labor. ${ }^{6}$ The compensations of skilled and unskilled labor are denoted by $r$ and $w$, respectively. Members of a poor household devote an (endogenous) fraction $1-\ell$ of their labor endowment to subsistence production and fraction $\ell$ to employment in the formal sector. Hence, they earn market income

\footnotetext{
${ }^{5}$ Our analysis can in principle also be applied to the context of developed economies to study labor-market equilibrium and the determination of factor prices in the "medium run" (Olivier J. Blanchard 1997; Robert M. Solow 2000). Instead of working in the informal economy, workers who do not get a job in the monopolistic sector are unemployed. Our analysis shows that the interaction of monopolistic firms' price-setting behavior and the distribution of income across households give rise to an upward-sloping "price setting curve" (higher average prices are associated with lower employment and higher unemployment). Adding a story about wage setting would let us end up with a "medium-run" equilibrium. A related earlier literature addresses the issue of whether there may be unemployment when the labor market is competitive but the product market is not (see Oliver Hart 1982; Claude d'Aspremont, Rodolphe Dos Santos Ferreira, and Louis-André Gérard-Varet 1990; Pierre Dehez 1985; and Joaquim Silvestre 1990; for a survey of this literature, see Silvestre 1993). This literature points out that unemployment may occur when firms' revenues are bounded and thus that labor demand may fall short of labor supply, even when the wage rate falls to zero. Such a possibility also arises in our model. While these papers have been concerned with the existence of unemployment equilibria in a representative-agent environment, our model focuses on the effect of heterogeneous consumers.

${ }^{6}$ In a previous version of this paper, we allowed for a more flexible specification of the composition of income source. More precisely, it was assumed that poor households earned their income predominantly from unskilled labor but had also some income from the other production factor. Similarly, for rich households. The present analysis can be extended to such a situation. We will come back to this issue in the discussion section below.
} 
$w \ell L / \beta$. Members of a rich household work in the formal sector only and earn market income $r H /(1-\beta)$.

All households have the same preferences over a continuum of differentiated products indexed by $j$. The various goods enter utility in a symmetric and separable way. It is assumed that the utility gain from consuming $x$ units of a particular good $j$ is given by $v(x(j))=s^{2} / 2-(s-x(j))^{2} / 2$ with $s$ being the saturation level.

Suppose $N$ differentiated goods are supplied at prices $\{p(j)\}_{j=0}^{N}$. A typical rich household decides how to allocate income $r H /(1-\beta)$ across the various differentiated goods and solves the problem

(1) $\max _{\left\{x_{p}(j)\right\}_{j=0}^{N}} \int_{0}^{N} \frac{s^{2}-\left[s-x_{R}(j)\right]^{2}}{2} d j \quad$ s.t. $\int_{0}^{N} p(j) x_{R}(j) d j \leq r H /(1-\beta)$,

which yields first order conditions

$$
\begin{array}{ll}
x_{R}(j)=s-\lambda_{R} p(j) & \text { if } p(j) \leq s / \lambda_{R}, \text { and } \\
x_{R}(j)=0 & \text { if } p(j)>s / \lambda_{R},
\end{array}
$$

where $\lambda_{R}$ is the marginal utility of income of a rich household.

A typical poor household has to decide how to allocate market income $\ell \times w L / \beta$ across differentiated products and how to allocate the labor endowment between employment in the formal sector and subsistence, respectively. For simplicity, it is assumed that one unit of unskilled labor yields subsistence output $\gamma$ and that one unit of the subsistence good yields one unit of utility. Hence, a poor household solves the problem

$$
\begin{gathered}
\max _{\left\{x_{P}(j)\right\}_{j=0}^{N}, \ell} \int_{0}^{N} \frac{s^{2}-\left[s-x_{P}(j)\right]^{2}}{2} d j+\gamma(1-\ell) L / \beta \\
\text { s.t. } \int_{0}^{N} p(j) x_{P}(j) d j \leq y_{P} \equiv w \ell L / \beta,
\end{gathered}
$$

which yields first order conditions

$$
\begin{array}{ll}
x_{P}(j)=s-\lambda_{P} p(j) & \text { if } p(j) \leq s / \lambda_{P}, \text { and } \\
x_{P}(j)=0 & \text { if } p(j)>s / \lambda_{P},
\end{array}
$$

and

$$
\begin{array}{ll}
\ell=1 & \text { if } w>\gamma / \lambda_{P}, \\
\ell \in[0,1] & \text { if } w=\gamma / \lambda_{P}, \\
\ell=0 & \text { if } w<\gamma / \lambda_{P},
\end{array}
$$


where $\lambda_{P}$ is the marginal utility of income of a poor household. To have an interesting problem, we assume $\gamma / s<a(1-\alpha)$. If this condition did not hold, no poor household would work in the formal sector. ${ }^{7}$

\section{B. Firms}

Firms in the modern sector of the economy sell the differentiated products on monopolistically competitive output markets. Setting up and running a modern firm requires an input of $F$ units of skilled labor. To produce output firms hire skilled and unskilled workers using the Leontief technology $X(j)=a \min \{\alpha H(j),(1-\alpha)$ $L(j)\}$, where $X(j)$ denotes the output of firm $j$ and $a>0$ and $\alpha \in(0,1)$ are technology parameters. With such technology, the unit cost of production is equal to $c=$ $a^{-1} \times(r / \alpha+w /(1-\alpha))$.

Which prices will firms set and which quantities will they supply? Consider a situation where $N$ firms have entered the market and consumers make consumption choices that obey the above first order conditions (2) and (4). The level of market demand faced by firm $j$ is simply the sum of individual demands. Using first order conditions for the respective types of consumers (noting that their $\lambda \mathrm{s}$ are different), the market demand function of this firm, $X(j, p(j))$, is given by

$$
X(j, p(j))= \begin{cases}0 & \text { if } p(j) \in\left[s / \lambda_{R}, \infty\right), \\ (1-\beta)\left[s-\lambda_{R} p(j)\right] & \text { if } p(j) \in\left[s / \lambda_{P}, s / \lambda_{R}\right), \\ s-\left[\beta \lambda_{P}+(1-\beta) \lambda_{R}\right] p(j) & \text { if } p(j) \in\left[0, s / \lambda_{P}\right) .\end{cases}
$$

In other words, horizontal aggregation of individual households' demand functions yields a piecewise linear market demand function with kinks at the reservation price levels of rich and poor consumers $s / \lambda_{R}$ and $s / \lambda_{P}$, respectively. When the price exceeds the reservation price of the rich, $p(j) \geq s / \lambda_{R}$, market demand is zero. For prices between the reservation prices of rich and poor, $p(j) \in\left(s / \lambda_{P}, s / \lambda_{R}\right]$, only rich consumers purchase and the market demand function is steep. For prices that fall short of the reservation price of the poor, $p(j)<s / \lambda_{P}$, both rich and poor consumers purchase and the market demand function is flat (Figure 1).

The monopolist supplying variety $j$ is negligibly small relative to the aggregate economy. It takes as given the unit cost of production $c$ (and hence factor prices $w$ and $r$ ) and the consumers' $\lambda \mathrm{s}$ (which depend on prices of all other goods and on consumers' incomes). The firm chooses the price $p(j)$ that maximizes the profit function

$$
[p(j)-c] X(j, p(j))
$$

\footnotetext{
${ }^{7}$ We could also assume that the rich have the option to work in the informal sector. Under the condition $(s / F)$ $\times\left(\phi^{2} /(1-\phi)\right)\left(s-(s /(1-\beta))\left(\phi^{2} /(1-\phi)\right)\right)>\gamma$-where $\phi=a \alpha(1-\alpha) L /(s F(\alpha H-(1-\alpha) L))$ and $a, \alpha$, and $F$ are technology parameters (see below) - we get $r \lambda_{R}>w \lambda_{P}$. This guarantees that, in the interesting equilibrium where the poor are indifferent between working in the formal and the informal sector, the rich are strictly better off when working in the formal sector.
} 


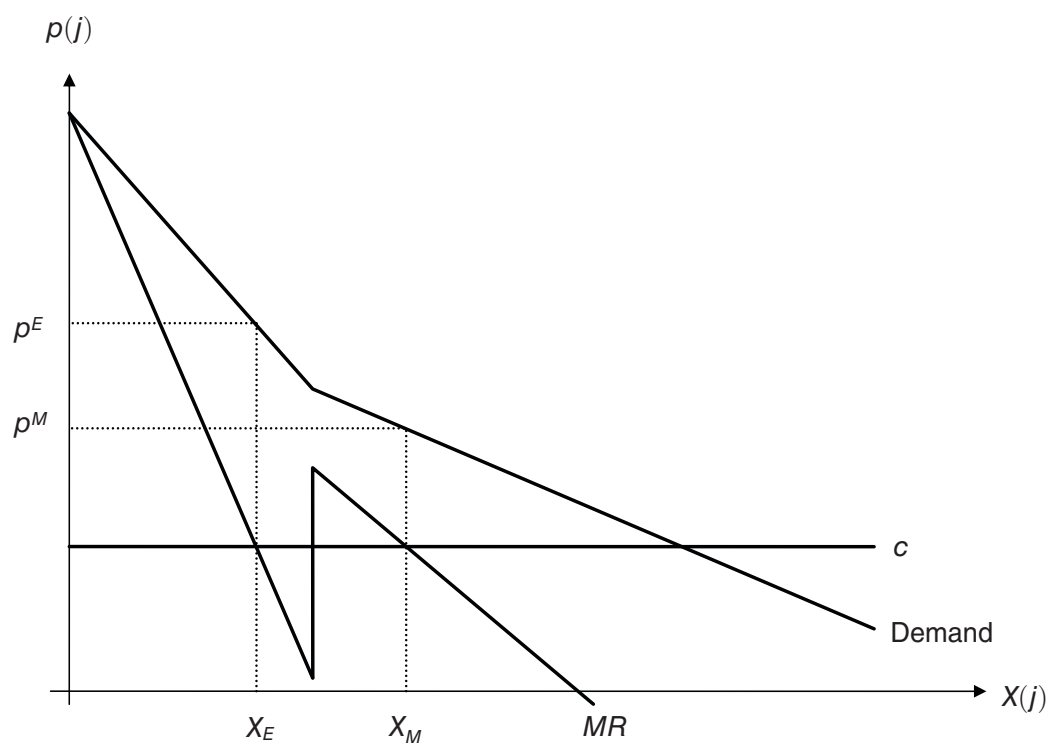

Figure 1. Aggregate Demand and Monopolistic Pricing Decision

With the piecewise linear market demand function (6) there are two candidates for the monopoly price: the profit-maximizing price along the steep segment (where only the rich buy) or the profit-maximizing price along the flat segment (where all consumers buy).

Maximizing the profit function yields the respective monopoly prices along these two segments as

$$
\begin{aligned}
& p(j)= \\
& \begin{cases}p^{E}=\frac{1}{2}\left[c+s / \lambda_{R}\right] & \text { along the steep segment, and } \\
p^{M}=\frac{1}{2}\left[c+s /\left(\beta \lambda_{P}+(1-\beta) \lambda_{R}\right)\right] & \text { along the flat segment. }\end{cases}
\end{aligned}
$$

Equation (7) shows that prices and mark-ups depend on the consumers' $\lambda$ s. In other words, price setting is determined by the distribution of income (and hence the distribution of $\lambda \mathrm{s}$ ). The larger the difference between $\lambda_{P}$ and $\lambda_{R}$ the larger will be the difference between $p^{E}$ and $p^{M}$.

Notice how this model with linear demand curves differs from the standard CES framework. In the CES framework, prices are just a multiple of marginal cost with a mark-up that reflects the consumers' elasticity of substitution between the various products. In the CES framework only equilibrium quantities, but not equilibrium prices, depend on consumers' marginal utility of income. This is different in the present situation. The ratio of a monopolistic producer's price over the unit costs of production also depends on the fundamental parameters of the model, not only preference, but also technology parameters and the distribution of income. The reason is that, with linear demand curves, the elasticity of demand falls along the demand curve. 


\section{An Asymmetric Equilibrium}

We now characterize an equilibrium where firms are indifferent between choosing the monopoly point of the steep and the flat segment of the market demand curve. Firms that supply along the steep segment are "exclusive producers:" they charge a high price and sell only to the rich. (By setting a high price they "exclude" poor households from the market). Firms that supply along the flat segment are "mass producers." Their prices are sufficiently low so that not only rich but also poor households can afford these goods.

\section{A. Mass and Exclusive Producers}

Here, we solve for the general equilibrium of the model in the asymmetric case. (The symmetric equilibrium will be briefly discussed later on). We are free to choose a numeraire so let us set $p^{M}=1$. For further use, the following lemma is helpful.

LEMMA 1: Denote, respectively, by $\left(X^{E}, p^{E}\right)$ and $\left(X^{M}, 1\right)$ the equilibrium quantities and prices supplied along the steep and the flat segment of the market demand curve. Quantities and prices satisfy the following equations:

$$
X^{E}=(1-\beta) s \frac{p^{E}-c}{2 p^{E}-c}
$$

and

$$
X^{M}=s \frac{1-c}{2-c} .
$$

The corresponding profits are $\Pi^{E}=\left(p^{E}-c\right) x^{E}$ and $\Pi^{M}=(1-c) x^{M}$.

\section{PROOF:}

We express the $\lambda \mathrm{s}$ in terms of $p^{E}$ and $c$ and substitute the resulting expressions into the individual demands (4) and (2). This yields

$$
\begin{array}{ll}
x_{P}^{E}=0, & x_{P}^{M}=s-\frac{s}{\beta}\left[\frac{1}{2-c}-\frac{1-\beta}{2 p^{E}-c}\right], \\
x_{R}^{E}=s-s\left[\frac{1}{2 p^{E}-c}\right] p^{E}, & x_{R}^{M}=s-s\left[\frac{1}{2 p^{E}-c}\right],
\end{array}
$$

where $x_{i}^{E}$ denotes the quantity purchased by a consumer of type $i \in\{R, P\}$ when the firm chooses the exclusive strategy (= charges the high price) and $x_{i}^{M}$ denotes the respective quantities when the firm chooses the mass consumption strategy (= charges the low price). The equilibrium output of exclusive producers is $X^{E}=(1-\beta) x_{R}^{E}$ and of mass producers, $X^{M}=\beta x_{P}^{M}+(1-\beta) x_{R}^{M}$. Using the above expressions for $x_{P}^{M} x_{R}^{E}$, and $x_{R}^{M}$ yields the values for $X^{E}$ and $X^{M}$. 
In an equilibrium with mass and exclusive producers both types of firms make the same profits $\Pi^{M}=\Pi^{E}$. Since firms are symmetric ex ante (i.e., every firm has the same demand- and cost-curves) they are indifferent between mass production and exclusion. Profits are $\Pi^{M}=(1-c) X^{M}$ for a mass producer and $\Pi^{E}=\left(p^{E}-c\right)$ $x^{E}$ for an exclusive producer. Using Lemma 1 this equilibrium condition can be expressed in terms of the endogenous variables $w$ and $p^{E}$

$$
s(1-\beta) \frac{\left(p^{E}-c\right)^{2}}{2 p^{E}-c}=s \frac{(1-c)^{2}}{2-c} .
$$

It is straightforward to verify that equation (9) can be solved for the price of the exclusive good $p^{E}$ and expressed as a function of marginal costs $c{ }^{8}$ For further use express the equilibrium condition (9) as $p^{E}=p(c)$ with $p^{\prime}(c)<0$. The negative relationship between $p^{E}$ and $c$ is very intuitive. A reduction in the marginal cost $c$ increases profits per unit of output by the same (absolute) amount both for exclusive producers and for mass producers. With prices unchanged, the larger market lets profits of mass producers increase more strongly than the profits of exclusive producers. To restore equilibrium, a higher price $p^{E}$ is required to ensure equal profits of the two types of producers.

\section{B. Firm Entry and the Allocation of Skilled Labor}

In the above discussion, we have assumed a given number of firms $N$. In this section, we discuss how firm entry is determined. Since only skilled labor can set up and run a modern firm, we will see that the determination of firm entry closely interacts with the allocation and compensation of skilled labor. Given the Leontief technology in the production of differentiated goods we have a fixed relation between the amount of skilled and unskilled labor, $H_{Y}$ and $L_{Y}$,

$$
\frac{H_{Y}}{L_{Y}}=\frac{1-\alpha}{\alpha}
$$

Using the fixed input ratio, it is straightforward to calculate, for a given amount of unskilled labor $L_{Y}$, the equilibrium allocation of skilled labor between production and firm creation. Denoted by $H_{N}$ is the amount of skilled labor engaged in setting up modern firms. As the fixed cost of firm creation equals $F$ units of skilled labor, we have $H_{N}=F N$. In equilibrium, skilled labor is fully employed, hence we have $H$ $=H_{N}+H_{Y}$. We now use expression (10) and make use of the fact that $L_{Y}$, the level of unskilled labor in production, is equal to the quantity of unskilled labor supplied $\ell L$. This allows us to express the number of entering firms $N$ as a function of $\ell$, the percentage of unskilled labor that finds employment in the formal sector

\footnotetext{
${ }^{8}$ Equation (9) is a quadratic equation in $p^{E}$. To see that $p^{E}$ is decreasing in $c$, it is straightforward to calculate the relevant root of $p^{E}$ as $p^{E}=p(c)=c+\left[(1-c)^{2}+(1-c) \sqrt{1-\beta(2-c) c}\right] /[(1-\beta)(2-c)]$.
} 


$$
N(\ell)=\frac{H-\frac{1-\alpha}{\alpha} \ell L}{F} .
$$

We note that $\ell$ is an endogenous variable to be determined below.

The latter two equations determine the allocation of skilled labor, but do not say anything about its compensation. In equilibrium, skilled workers have to be indifferent between working in the production of final output or providing skills for firm creation. We can determine $r$, the compensation of skilled labor from the zero-profit condition for firm entry. In equilibrium, unexploited profit opportunities may not exist, hence the fixed entry cost, $r F$, may not fall short of the operating profits of an active (exclusive or mass) producer $\Pi^{M}=\Pi^{E}$. Using Lemma 1, we can express $r$ as a function of unit production costs $c$ as

$$
r(c)=\frac{s}{F} \frac{(1-c)^{2}}{2-c}, \text { with } r^{\prime}(c)<0 .
$$

A higher unit cost of production reduces profits, hence skilled labor becomes, ceteris paribus, less valuable.

Recall that with Leontief technology the unit cost of production is given by $c$ $=a^{-1}(r / \alpha+w /(1-\alpha))$. From this relation, we can express $w$, the compensation of unskilled labor, as a function of $c$

$$
w(c)=\left(a c-\frac{s}{\alpha F} \frac{(1-c)^{2}}{2-c}\right)(1-\alpha), \text { with } w^{\prime}(c)>0 .
$$

\section{The Market for Unskilled Labor}

We are now ready to address the variable of our main interest: the equilibrium level of employment in the formal sector. It turns out that the equilibrium conditions can be reduced to two equations in the two unknowns $c$ and $\ell$. We call the first of these two relations the "general-equilibrium demand relation for unskilled labor." This relation is defined as follows.

DEFINITION 1: The general-equilibrium demand relation for unskilled labor is given by combinations of $(c, \ell)$ along which $(i)$ households obey first order conditions (2) and (4) and exhaust their budget constraints; (ii) firms maximize operating profits, i.e., mass producing firms set price $p^{M}=1$ and sell output $X^{M}(c)$, and exclusive firms set price $p^{E}=p(c)$ and sell quantity $X^{E}(c)$ (see Lemma 1); (iii) employment is $\ell$ L i.e., any given amount of unskilled labor supplied finds a job in the formal sector; (iv) the free entry condition (11) is satisfied.

Notice that, while the above relation imposes full employment of a given amount of labor $\ell L$ supplied by poor households to the formal sector, this condition does not require that the quantity $\ell L$ is optimal from the perspective of poor households. 
(This optimality requirement is captured by the second general-equilibrium relation in $c$ and $\ell$, see below.)

We proceed by deriving the general-equilibrium labor-demand relation. In an asymmetric equilibrium, there are mass producers with unskilled labor demand $[a(1-\alpha)]^{-1} X^{M}$ and exclusive producers with unskilled labor demand $[a(1-\alpha)]^{-1}$ $\times X^{E}$. Denoting by $n$ the share of mass producers among all active firms, the aggregate demand for unskilled labor is given by $[a(1-\alpha)]^{-1}\left[n X^{M}+(1-n) X^{E}\right] N$. Notice that $X^{M}$ and $X^{E}$ depend only on $c$, but not on $\ell$, see Lemma 1 , and that the equilibrium number of active firms $N$ depends only on $\ell$, but not on $c$, see equation (11).

It remains to be determined how $n$ is related to $c$ and $\ell$. Clearly, the percentage of mass producers $n$ is of crucial interest in the present context. Intuitively, an economy that concentrates on mass production will generate better employment opportunities for unskilled labor than an economy in which the formal sector focuses primarily on the satisfaction of wants of the rich. We can express the percentage of mass producers $n$ in terms of $c$ and $\ell$ using the poor households' budget constraint $w \ell L / \beta$ $=n N x_{P}^{M}$. Making use of Lemma 1 and equations (11) and (13) lets us write

$$
n(c, \ell)=\frac{w(c)}{x_{P}^{M}(c)} \frac{\ell L}{\beta N(\ell)} .
$$

Notice that $n_{\ell}(c, \ell) \equiv \partial n(c, \ell) / \partial \ell>0$. This is quite intuitive. When the unskilled households devote much of their labor force to employment in the formal sector, this will generate a higher formal-sector income and, hence, high demand for products in this sector. This induces many firms to become mass producers. We also have $n_{c}(c, \ell) \equiv \partial n(c, \ell) / \partial c>0$. There are two effects at work. On the one hand, higher production costs $c$ are associated with higher wages from (13) and, thus, a higher aggregate income by poor households $w(c) \ell L$. This will lead to a higher prevalence of mass production. On the other hand, a higher $c$ also implies that each producer will reduce their output (From Lemma 1, we have $\partial X^{M} / \partial c<0$.) This lower output arises from lower sales to both rich and poor households, hence, $\partial x_{P}^{M} / \partial c<0$. This means that the poor will spread their income across a larger number of goods. In sum, an increase in $c$ increases $n$, i.e., higher production costs are associated with more mass consumption.

We can now discuss how $c$ and $\ell$ are related along the general-equilibrium labor-demand relation. It turns out convenient to define the excess demand function $\Psi(c, \ell)$ given by the difference between unskilled labor demand $[a(1-\alpha)]^{-1}$ $\times\left[n X^{M}+(1-n) X^{E}\right] N$ and unskilled labor supply $\ell L$. In general equilibrium we have

$$
\Psi(c, \ell) \equiv \frac{N(\ell)}{a(1-\alpha)}\left[n(c, \ell) X^{M}(c)+(1-n(c, \ell)) X^{E}(c)\right]-\ell L=0
$$

The first term on the right-hand side of (15) nicely shows how the demand of formal-sector firms for unskilled labor comprises of three different components and how these components demand on $c$ and $\ell$ : the number of active firms $N(\ell)$ determined by (11); the percentage of mass producers among active firms $n(c, \ell)$ given 
by equation (14); and the labor demands of mass producers and exclusive producers, respectively, given by Lemma 1 .

To characterize the curvature of the general-equilibrium labor-demand relation in $(c, \ell)$ space we examine the derivatives of the function $\Psi(c, \ell)$ with respect to $c$ and $\ell$. Note first that $\Psi_{\ell}(c, \ell)<0 .{ }^{9}$ This says that an increase in labor supply $\ell$ is not fully matched by an increase in labor demand due to higher market income of the poor $w \ell L$. Notice further that the sign of $[a(1-\alpha)] \Psi_{c}(c, \ell)$ $=N n_{c}\left[X^{M}-X^{E}\right]+N\left[n \partial X^{M} / \partial c+(1-n) \partial X^{E} / \partial c\right]$ is not clear a priori. On the one hand, an increase in $c$ is associated with higher real incomes of poor households. The resulting increase in demand for differentiated products stimulates the incentive for mass production. This purchasing power effect is captured by the term $n_{c}\left[X^{M}(c)-X^{E}(c)\right]>0$. On the other hand, higher unit costs $c$ induce firms to reduce employment and production. This familiar cost effect is captured by the term $n \partial X^{M} / \partial c+(1-n) \partial X^{E} / \partial c<0 .{ }^{10}$

We turn to labor supply which yields a second condition in $c$ and $\ell$. The labor supply relation takes account of optimal labor supply choices by poor households. It is defined as follows.

\section{DEFINITION 2: The general-equilibrium supply relation of unskilled labor are} combinations of $(c, \ell)$ along which $(i)$ all poor households obey first order conditions (4) and (5); and (ii) poor households purchase the quantity $x_{P}^{M}(c)$ from mass producers (see Lemma 1).

We have assumed that poor households allocate their labor supply optimally between the formal sector and subsistence. Hence, in equilibrium they need to be indifferent between working in the formal sector or working in subsistence production. Optimal labor supply choices by poor households obey first order conditions (4) and (5). Combining the two conditions yields $\gamma / w=s-x_{P}^{M}$. From (13) and Lemma 1 , we know that, in general equilibrium, both $w$ and $x_{P}^{M}$ depend only on $c$,

\footnotetext{
${ }^{9}$ To see this, note that $[a(1-\alpha)] \Psi_{\ell}(c, \ell)=n_{\ell}\left[X^{M}-X^{E}\right] N+\left[n X^{M}+(1-n) X^{E}\right] \partial N / \partial \ell-a(1-\alpha) L$.

To sign the derivative, observe that $n_{\ell}=n(1-(\ell / N) \partial N / \partial \ell)$ and $N\left[n X^{M}+(1-n) X^{E}\right]<a(1-\alpha) L$.

${ }^{10}$ It is not straighforward to derive a meaningful condition under which the purchasing power effect dominates the cost effect and vice versa. We therefore undertook a large number of simulations to learn the slope of the general equilibrium labor-demand relation. In all cases, we found that the purchasing power effect dominates the cost effect, so that $\Psi_{c}(c, \ell)>0$, and the general-equilibrium labor-demand relation is upward sloping in $(c, \ell)$ space. The reason for the apparent dominance of the purchasing power effect is our assumption that income classes and income sources coincide. An increase in unskilled wages benefits the poor (and even harms the rich). In contrast, if both rich and poor households had the same relative endowments with skilled and unskilled labor (but the rich were better endowed with both factors), both types of households would be equally affected by a change in factor prices. In that case the purchasing power effect vanishes. This is discussed in a previous version of this paper (Foellmi and Zweimüller 2006b).
} 
but do not depend on $\ell$. Hence, $\ell$, the optimal fraction of unskilled labor supplied to the formal sector, is given by ${ }^{11}$

$$
\begin{array}{ll}
\ell=0 & \text { when } \gamma / w(c)>s-x_{P}^{M}(c) \\
\ell \in[0,1] & \text { when } \gamma / w(c)=s-x_{P}^{M}(c) \\
\ell=1 & \text { when } \gamma / w(c)<s-x_{P}^{M}(c) .
\end{array}
$$

Condition (16) says that there is a cutoff level for the unskilled wage, $w\left(c^{*}\right)$, defined as $\gamma / w\left(c^{*}\right)=s-x_{P}^{M}\left(c^{*}\right)$. The cutoff level is larger than zero (the wage rate (13) becomes zero at $c>0$ ) and smaller than one (because $\gamma / s<a(1-\alpha)$ by assumption). When the unskilled wage falls short of this cut off, poor households remain in subsistence; and they prefer employment in the formal sector if the wage exceeds this critical level. Only when the wage is exactly equal to $w\left(c^{*}\right)$ an interior solution where poor households devote their labor resources partly to the formal sector and partly the subsistence sector prevails.

\section{A Symmetric Equilibrium}

Before we start to analyze the role of economic inequality for the size and employment of the formal sector, let us briefly address the situation of a symmetric equilibrium. Since inequality is endogenous, inter alia determined by factor prices, it could be that parameter values are such that low inequality arises in equilibrium in which the equilibrium outcome is symmetric, i.e., all firms are mass producers.

The market for skilled labor works just like it does in the asymmetric equilibrium, so equations (11), (12), and (13) continue to hold. By definition of a symmetric equilibrium, all formal-sector firms are mass producers and supply quantity $X^{M}(c)$ $=(1-c) /(2-c)$ at price $p^{M}=1$. The general-equilibrium labor-demand relation is therefore given by

$$
\ell L=\frac{s N(\ell)}{a(1-\alpha)} \frac{1-c}{2-c} .
$$

Notice that in the symmetric equilibrium the demand for labor is falling in $c$. This is because only the cost effect is at work that induces mass producers to supply less output. The purchasing power effect of a higher $c$ is not at work in the symmetric case ( since there are no exclusive firms who could become mass producers). Income distribution does not have an effect on demand for labor in the symmetric case because quadratic preferences are non-homothetic, but belong to the HARA class.

\footnotetext{
${ }^{11}$ Notice that the condition (16) is not a labor supply curve in the usual sense. Just like the general equilibrium labor demand curve defined above, the labor supply curve (16) requires that general quilibrium conditions hold. In particular, all households are required to supply their labor power optimally, and all mass producer firms sell the quantity $x_{P}^{M}(c)$ to poor households.
} 
The latter implies that the marginal propensity to consume is the same across all income classes as long as a product is consumed.

Just like in the asymmetric case, the second equilibrium relation in $c$ and $\ell$ needs to consider optimal labor supply choices by poor households. The first order conditions (4) and (5) still hold, and we have $\gamma / w=s-x_{P}^{M}$. The poor households' budget constraint requires $x_{P}^{M}(c, \ell)=w(c) \ell L /(\beta N(\ell))$ in a symmetric equilibrium. As Lemma 1 applies only in the asymmetric case, but does not apply in a symmetric equilibrium, the equilibrium level of $x_{P}^{M}$ is no longer independent of $\ell$. Hence, the optimal fraction of unskilled labor supplied to the formal sector is given by

$$
\begin{array}{ll}
\ell=0 & \text { when } \gamma / w(c)>s \\
\ell \in[0,1] & \text { when } \gamma / w(c)=s-w(c) \ell L /(\beta N(\ell)) \\
\ell=1 & \text { when } \gamma / w(c)<s-w(c) L /(\beta N(1)) .
\end{array}
$$

Equations (17) and (18) form the system of two equations in the two unknowns $c$ and $\ell$. Notice the difference in the general-equilibrium labor-supply curve between the symmetric and the asymmetric case. In a symmetric equilibrium, a higher $\ell$ lets poor households expand the consumption of differentiated goods mainly along the intensive margin, i.e., by increasing $x_{P}^{M}$. Given the consumers' utility function this implies decreasing marginal utility. ${ }^{12}$ Since the marginal utility from consuming less subsistence goods is constant, a higher wage $w(c)$ is needed to induce poor households working in the formal sector. This implies an upward sloping general-equilibrium labor-supply curve. (Recall that $w(c)$ is increasing in $c$ from (13)). The situation is different in the asymmetric equilibrium where the increased income from a higher $\ell$ lets poor households expand their consumption along the extensive margin, i.e., they purchase more differentiated goods, each at the same quantity $x_{P}^{M}(c)$. (Recall that, from Lemma 1 , the quantity $x_{P}^{M}(c)$ is independent of $\ell$.) Together with the constant marginal utility of the subsistence good this gives a flat general-equilibrium labor-supply curve.

\section{Existence of Equilibrium}

The previous sections characterized the properties of both an asymmetric and a symmetric equilibrium. This section will prove the existence of an equilibrium formally.

In Section III, we have characterized a symmetric equilibrium where all firms are mass producers and sell to all households. To check whether this is a Nash equilibrium, we consider a situation where all other firms charge a low price and sell to all consumers, and then we check whether a single firm has an incentive to deviate, i.e., set a high price and become an exclusive producer. It turns out that the exclusion strategy is worthwhile if the income disparities between rich and poor households are sufficiently large. This is very intuitive. Were rich and poor almost identical, the steep segment of the market demand curve would become irrelevant and all firms would prefer to benefit from the large market. However, when the income disparities are

\footnotetext{
12 Since the total number of firms $N(\ell)$ decreases when $\ell$ increases, poor households have to spread their consumption over a more narrow range of goods which increases $x_{P}^{M}$ (and hence decreases marginal utility) even further.
} 
sufficiently large, it pays to exploit the higher willingness to pay by rich households and the exclusion strategy becomes a profitable option. The general equilibrium in a symmetric equilibrium is characterized by (17) and (18). It turns out useful to express the equilibrium level of marginal cost by the implicit expression

$$
c_{\text {sym }}=\frac{H-(2 \zeta+1) \frac{1-\alpha}{\alpha} \ell L}{H-(\zeta+1) \frac{1-\alpha}{\alpha} \ell L},
$$

where $\zeta=\alpha a F / s$ and $0 \leq \ell \leq 1$. If $\ell \leq 1$, it is determined by $\gamma / w\left(c_{s y m}\right)=s-$ $w\left(c_{s y m}\right) \ell L /(\beta N(\ell))$. Using (17) and (18), we see that $c_{s y m}$ does not change if $H$ and $L$ change proportionally. The following proposition gives a necessary and sufficient condition for the existence of a symmetric equilibrium.

PROPOSITION 1: A symmetric equilibrium exists if and only if $[(1-\beta)(2-\xi)+$ $(1-\xi) \xi]^{2} /\left[4\left((1-\beta)(2-\xi)-(1-\xi)^{2}\right)\right]<1$ with $\xi=c_{s y m}$.

\section{PROOF:}

See Appendix A.

If this condition is violated, there cannot exist a symmetric equilibrium becauseas shown in Appendix A-a symmetric equilibrium does not constitute a Nash equilibrium for the monopolistic firms. The reverse statement, however, is not true. If the condition in Proposition 1 holds, a symmetric equilibrium exists, but there may be asymmetric equilibria as well.

Proposition 1 allows us to separate the two equilibrium regimes. Note that we may express the condition in the proposition in the terms of marginal costs (see Figure 2 below): If $c<\hat{c}$ where $[(1-\beta)(2-\hat{c})+\hat{c}(1-\hat{c})]^{2} /[4((1-\beta)(2-\hat{c})-$ $\left.\left.(1-\hat{c})^{2}\right)\right]=1$, a symmetric equilibrium cannot exist.

The condition always holds if $\xi \rightarrow 1$, and is always violated if $\xi \rightarrow 0$. It is shown in the proof of Proposition 1 that the left-hand side of the condition decreases in $\xi$. A fall in $\xi$ implies that an asymmetric equilibrium becomes more likely. The reason is the following. A lower level of $[H-(2 \zeta+1)((1-\alpha) / \alpha) \ell L] /[H-(\zeta+1)((1-\alpha) / \alpha) \ell L]$ means, in equilibrium, higher production per firm, and allows an increase in consumption for both groups. This increases markups as both types of consumers purchase at a less elastic point on their individual demand curves. However, since rich consumers are closer to their saturation point than the average consumer, this causes a disproportionate decrease in their demand elasticity. In other words, when the ratio in (19) is lower, markups increase more strongly when firms sell exclusively to the rich and increase less strongly when they sell on mass markets. As a result, the exclusion strategy becomes more attractive. Hence, the above condition in Proposition 1 is less likely to hold with higher inequality, that is when $\zeta$ is large. This confirms our claim that, when inequality is sufficiently high, an asymmetric outcome will prevail.

The following Proposition 2 states that at least one equilibrium (either symmetric or asymmetric) exists. This implies if no symmetric equilibrium exists, the remaining equilibrium (be it single or multiple) must be asymmetric. 


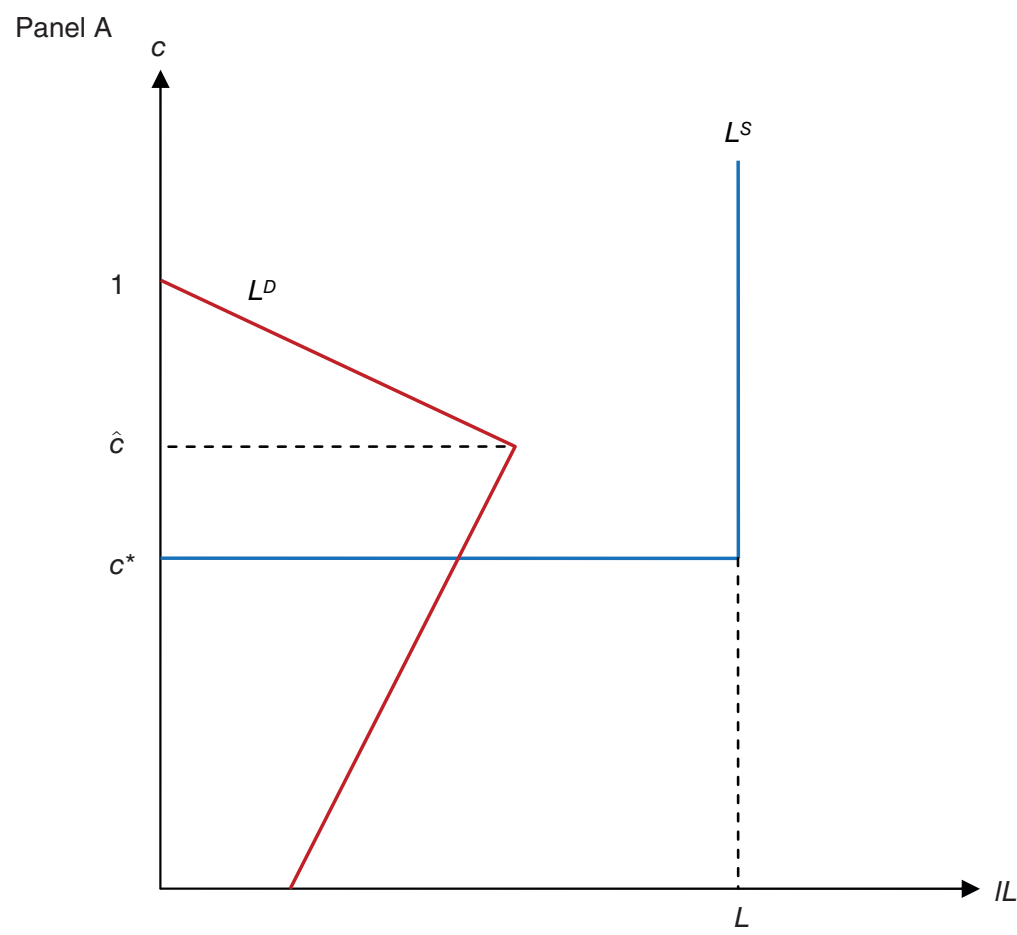

Panel B

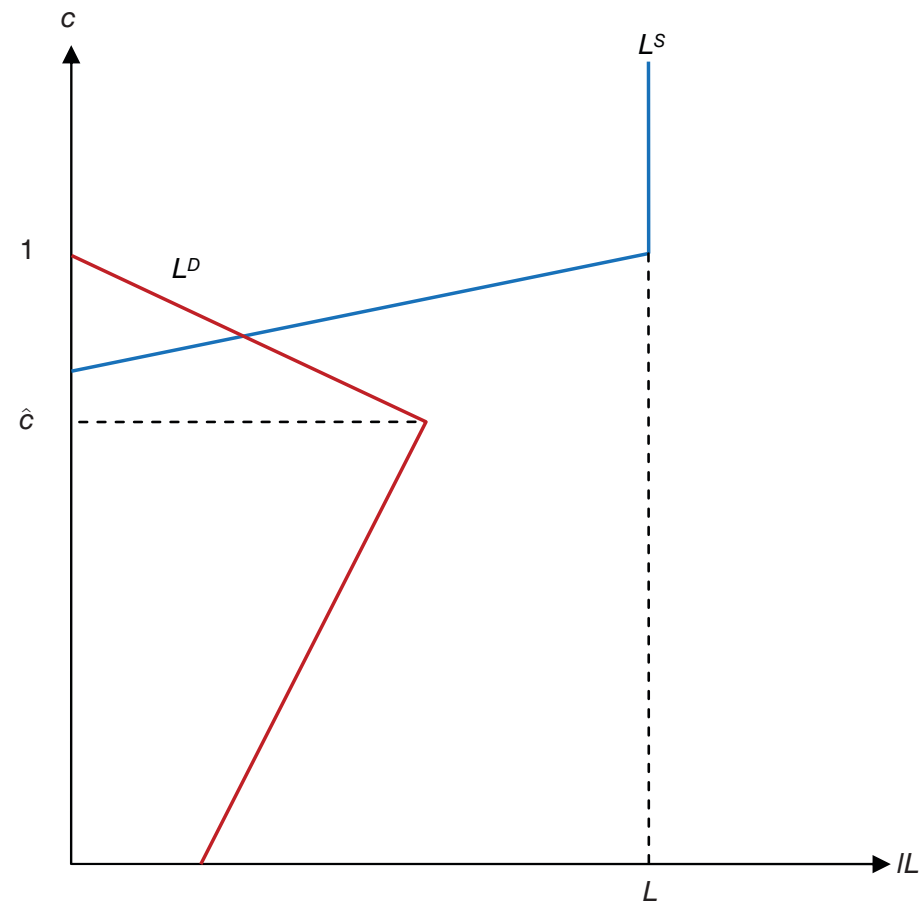

Figure 2. General EQUilibrium 


\section{PROPOSITION 2:}

(i) An asymmetric equilibrium prevails when $(c, \ell)$ combinations are such that $n(c, \ell)<1$ in (14) and equations (15) and (16) hold.

(ii) A symmetric equilibrium prevails when $(c, \ell)$ combinations are such that $n(c, \ell) \geq 1$ and equations (17) and (18) hold.

\section{PROOF:}

Consider first $(c, \ell)$ combinations where $n(c, \ell)<1$. We examine the axes intercepts in the $(c, \ell)$ space of the general-equilibrium labor demand $[N(\ell) / a(1-\alpha)]\left[n(c, \ell) X^{M}(c)+(1-n(c, \ell)) X^{E}(c)\right]=\Psi(c, \ell)+\ell L$. First, $\Psi(c, 0)$ $=[(H / F) / a(1-\alpha)] X^{E}(c)>0$, hence $\ell$ fulfilling (15) must be greater than 0 . Second, $\Psi(1, \ell)+\ell L=-\ell L+\ell L=0$. We know that $0<c^{*}<1$ in (16). Hence, $1>c \geq c^{*}$ and $0<\ell \leq 1$ solve (15) and (16) simultaneously. For $(c, \ell)$ combinations where $n(c, \ell) \geq 1$, the equilibrium is symmetric. For $c \geq \hat{c}$, GE labor demand simplifies to $[N(\ell) / a(1-\alpha)] X^{M}(c)$ (see Figure 2 below). The vertical axis intercept is still given by $(c, \ell)=(1,0)$.

\section{Inequality and Formal-Sector Employment}

We are now ready to address the question of our main interest. How does the extent of economic inequality affect the poor households' employment opportunities in the formal sector? We will focus on an asymmetric equilibrium because this case captures the main features that characterize a typical developing country: high inequality and limited entry. However, to give the comprehensive picture we also capture the case where parameters are such that a symmetric equilibrium emerges.

It turns out convenient to rely on a graphical exposition where we draw the general-equilibrium demand and supply relations for unskilled labor in $(c, \ell)$ space (Figure 2). Consider the labor demand relation. For sufficiently low values of $c<\hat{c}$ (see Proposition 1), unskilled wages $w(c)$ are so low and inequality so high that the general equilibrium will be asymmetric and equilibrium relations (15) and (16) are relevant. The switch from an asymmetric to a symmetric equilibrium occurs at $c=\hat{c}$. When costs approach this critical level from below, the fraction of firms that become mass producers converges towards unity. When $c \geq \hat{c}$, we end up in an symmetric equilibrium where labor demand and supply relations (17) and (18) are relevant. The other critical level of $c$ is $c^{*}$, at which poor households are indifferent between working in the formal sector or remaining in subsistence (see discussion following equation (16). Obviously, the supply relation (16) is relevant only when $\hat{c}>c^{*}$ and the supply relation (18) is relevant for values of $c \geq \hat{c}$.

Figure 2 captures the case of an asymmetric equilibrium. The labor demand relation is assumed to be upward sloping in the asymmetric region $c<\hat{c}$. ${ }^{13}$ At $c=\hat{c}$ there is a kink and in the symmetric region $c \geq \hat{c}$ the labor demand relation is downward sloping. Panel A of Figure 2 is drawn for the case $c^{*}<\hat{c}$ so that an intersection

\footnotetext{
${ }^{13}$ We found upward sloping labor demand relations in all our simulations, see previous footnote 12.
} 


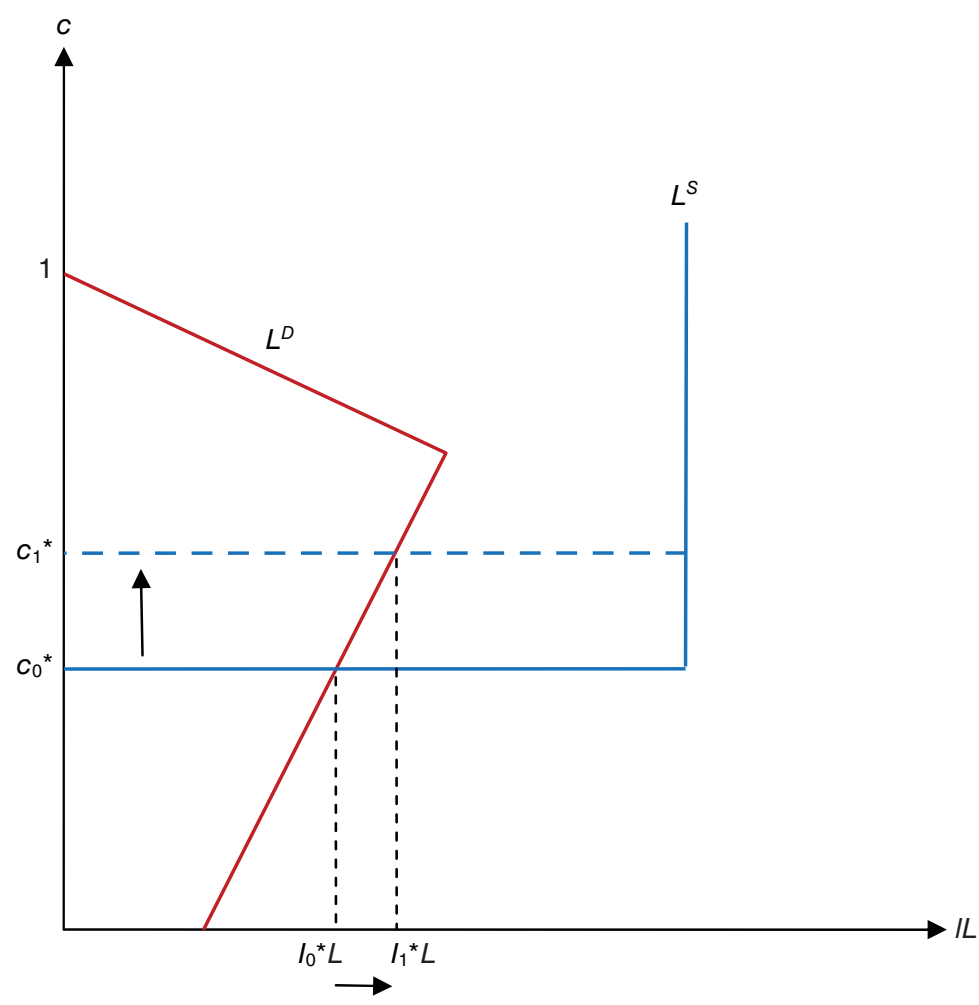

FigURE 3. RISE IN $\gamma$

between the curves occurs in the flat part of the labor supply relation. Alternatively, panel B assumes that $c^{*}>\hat{c}$ so that an equilibrium where both the formal and the informal sector are active must be a symmetric one.

In what follows, we study the consequences of changes in inequality. In the context of our model, there are two crucial parameters that determine the distribution of formal-sector income: productivity in subsistence $\gamma$, and the population size of the poor $\beta$. Since our analysis wants to capture changes in inequality in the context of a developing economy, we concentrate on an asymmetric outcome. Let us first consider the impact of higher productivity in subsistence $\gamma$ (Figure 3). Notice that $\gamma$ affects the labor supply relation (16), but does not show up in the labor demand relations (15) and (17). An increase in $\gamma$ shifts the labor supply relation up. With a positively sloped labor demand relation as in Figure 3, this leads to both a higher $c$ and higher $\ell$. In other words, an improvement in subsistence productivity may foster formal-sector employment of unskilled workers and increase formal-sector wages of unskilled workers.

\section{PROPOSITION 3:}

(i) An increase in subsistence productivity $\gamma$ may lead to an increase of unskilled wages $w$ and unskilled employment $\ell L$. 
(ii) An increase in employment is associated with more mass producing firms $n N$ and less exclusive firms $(1-n) N$. The total number of active firms $N$ decreases.

(iii) An increase in $\gamma$ may increase welfare of rich households.

\section{PROOF:}

Part (i) of the proposition states that the higher wages associated with an increase in $\gamma$ may lead to an increase in employment of formal-sector firms. The reason is that the increased purchasing power of poor households induces many exclusive producers to become mass producers. These firms lower their prices to levels that poor households can afford and hire more (skilled and unskilled) workers to satisfy the increased demand for their products. Working against this, the higher marginal costs (through wages) reduce the levels of employment of both mass and exclusive producers. However, when the former purchasing power effect dominates the latter cost effect (which is equivalent for the general-equilibrium labor-demand relation to have a positive slope) more unskilled workers find employment in the formal sector. ${ }^{14}$

Notice that the result in part (i) of the proposition is prima facie surprising. The utility functions in (1) and (3) assume a constant marginal utility for the subsistence good whereas marginal utilities are decreasing for differentiated products. Hence, one would expect more economic activity in the subsistence sector when subsistence productivity increases (while productivity in the modern sector remains unchanged). Proposition 1 states the opposite outcome is possible and simulations show that such an outcome is very likely. In sum, purchasing power effects arising from non-homothetic preferences over differentiated products may be strong as the associated changes in price elasticities lead to changes in market sizes, equilibrium prices, and markups triggering employment effects that may be larger than the cost effects of higher wages for unskilled labor in the formal sector.

Part (ii) of the proposition says that the increase in unskilled employment is associated with a higher prevalence of mass consumption, but less entry of firms, see equation (11). In other words, the lower inequality in society associated with a higher $\gamma$ lowers entry, but leads to a concentration of output in mass production.

Finally, part (iii) of the proposition states that not only poor households but also rich households may benefit from lower inequality. This is surprising as higher unskilled wages are associated with lower wages for skilled workers and hence a reduction in their income. However, rich households benefit from the low prices associated with the concentration on mass consumption. This effect may overcompensate rich households for the lower production variety due to less firm entry. ${ }^{15}$

\footnotetext{
14 Simulations show that a positive slope of the general-equilibrium labor-demand relation is the likely case in an asymmetric equilibrium. In simulations, we were unable to find a single parameter constellation where this relation is downward sloping. Hence, the statement Proposition 1 does not hold just locally, but it is the relevant outcome in the context of the present framework.

${ }^{15}$ To see this, consider the following parameter constellation $H=L=F=1, a=2, \alpha=\beta=0.5$, and $s=4$. With $\gamma>0.48$ welfare of rich households increases when $\gamma$ rises.
} 


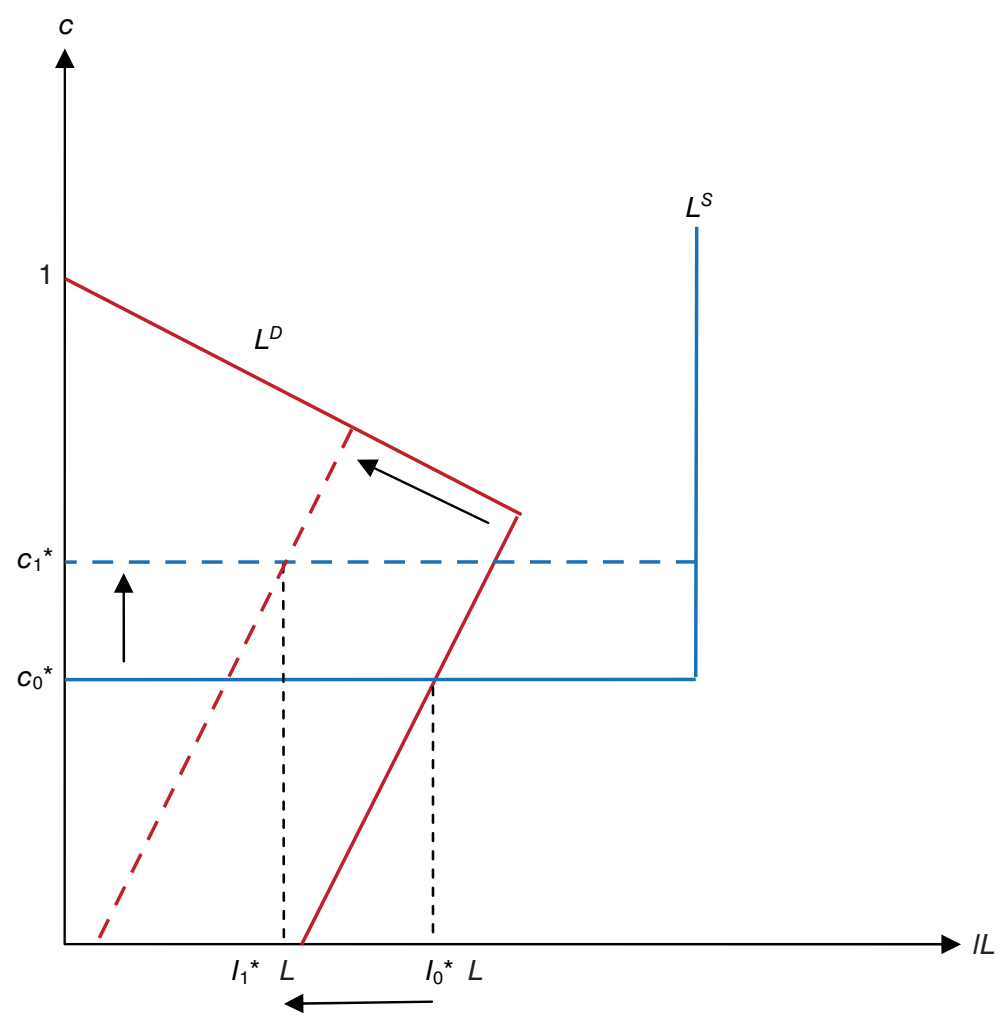

Figure 4. RISE IN $\beta$

Let us next examine a change in the population share of the poor $\beta$ (Figure 4). The parameter $\beta$ shows up both in the labor demand relation via its effect on the percentage mass producers $n$ and the output of exclusive producers $X^{E}$ (see equation (14) and Lemma 1 . The labor supply relation is affected by $\beta$ via consumption level of the poor $x_{P}^{M}$. It can be shown that an increase in $\beta$ shifts the labor demand relation to the left and shift the labor supply relation upwards.

LEMMA 2: A higher $\beta$ lowers employment for given c, i.e., it shifts the labor demand schedule to the left.

\section{PROOF:}

See Appendix B.

PROPOSITION 4: A higher extent of inequality due to a higher population share of poor households $\beta$ tends to reduce employment of unskilled workers $\ell$ and leads to more firm entry $N$, but less mass production $n N$.

The proposition states that there is a negative relationship between economic inequality and formal-sector employment when inequality is generated by a 
change in the second distribution parameter of the model, the group share of the poor $\beta$. Recall that formal-sector income of a poor household is $w \ell L / \beta$, and the income of a rich household is $r H /(1-\beta)$. Hence, a higher $\beta$ increases inequality both directly via population shares and indirectly via relative incomes. ${ }^{16}$ Inspection of the labor demand relation (15) shows that an increase in $\beta$ generates two effects. The first effect works through the reduction in the income of poor households when $\beta$ rises. Consequently, less goods are sold to the poor, i.e., $\partial n / \partial \beta<0$ as follows from the proof of Lemma 2 . The second effect works via the effect of $\beta$ on prices and market sizes of exclusive goods. A higher $\beta$ implies that there are fewer rich households which per se tends to reduce output and employment of exclusive producers. However, a higher $\beta$ also increases the incomes of rich households which works in the opposite direction. Hence, the direction of the second effect is a priori unclear. However, the overall effect of an increase in $\beta$ is to lower employment of unskilled labor. To see this, note that for a given $c$ and $\ell$ (and hence a given $w$ and given $r$ ), there is no direct effect on incomes of the poor and the rich as a group, w $\ell L$ and $r H$. With less mass producers the rich spend a larger fraction of their income on exclusive goods and this reallocation of expenditures reduces overall employment. The reason is that the higher prices (but identical labor requirements) of exclusive goods imply that a given amount of expenditures spent on exclusive goods generates lower labor demand than the same amount spent on mass products. Hence the labor demand relation shifts to the left.

The general-equilibrium labor-supply relation shifts up when $\beta$ rises. Note that we have $\partial x_{P}^{M} / \partial \beta>0$. A larger $\beta$ raises, in equilibrium, the price ratio between exclusive and mass products. Hence, markups on all products must rise due to (A3). Higher markups are only compatible with higher quantities in equilibrium, because the elasticity of demand decreases in consumption. To keep workers indifferent between working in subsistence and working in the formal sector a higher wage $w(c)$ (and hence higher marginal $\operatorname{cost} c$ ) is needed. Since all our simulations rendered an upward sloping labor demand, the net effect on employment is unclear (Figure 4). However, we were unable to find a parameter constellation where employment has risen after $\beta$ had increased.

Finally, the effects of higher inequality on industry structure $n N$ and firm entry $N$ are very similar irrespective of whether higher inequality is generated from a higher $\beta$ or from a lower $\gamma$. As long as the labor demand is upward sloping, in both cases a more unequal society concentrates its resources less in mass production and generates more overall firm entry from which only the rich benefit.

The above discussion has concentrated on an asymmetric equilibrium, which is the case of our main interest. In the less interesting situation of a symmetric equilibrium, increases in inequality (due to a higher $\beta$ and/or a lower $\gamma$ ) leave the labor demand relation unaffected (see equation (17)) and shift the labor supply relation down. Hence, in equilibrium, more inequality is associated with higher formal-sector employment, because lower unskilled wages induces firms (all of them are mass producers) to hire more workers.

16 The Lorenz curve is piecewise linear with population shares $\beta$ and $1-\beta$ and income shares $w \ell L / Y$ and $r H / Y$ where aggregate income is $Y=w \ell L+r H$. 


\section{How General Are Our Results?}

In this paper, we have presented a model where consumers have non-homothetic preferences, and where the distribution of income plays a central role for aggregate employment. Our model has started out from simplifying assumptions. Let us briefly discuss the robustness of our results with respect to these assumptions.

Preferences.- - In our model, we have assumed a quadratic subutility function. We used the quadratic specification because it keeps the analysis simple and yields closed form solutions. The quadratic subutility function has two crucial properties. First, the marginal utility from consuming the first unit is finite, $v^{\prime}(0)=s<\infty$. This is a necessary condition for an equilibrium where poor consumers do not want to afford all goods (i.e., the nonnegativity constraint may become binding). Second, the quadratic specification implies a linear demand curve of a particular consumer and a price elasticity of demand that decreases in consumed quantity. Denoting by $\eta(c)$ the price elasticity of demand, we have $\eta(c)=(s-c) / c$, which is decreasing in $c .{ }^{17}$

Our analysis extends in a straightforward way to the subclass of hyperbolic absolute risk aversion (HARA) preferences that feature $v^{\prime}(0)<\infty$. HARA preferences with this property also feature decreasing price elasticities along individual demand curves. Provided that this elasticity falls below unity at a finite $c$, equilibria with informal-sector employment are possible under appropriate parameter values. We elaborate this in greater detail in Appendix C. Going beyond HARA, things become more complicated because the distribution of income affects consumption along not only the extensive margin (how many consumers can purchase a certain good) but also the intensive margin. As Engel-curves are no longer linear, market demand curves depend on the distribution of income, even in symmetric equilibria. ${ }^{18}$

While our analysis relied on non-homothetic preferences, our particular specification of non-homotheticities differs from most previous papers. In our framework, non-homotheticities operate entirely via the demand functions for differentiated products of the formal sector. These demand functions feature decreasing price elasticities and finite reservation prices, thus generating interesting interactions between income inequality on the one side and price, markups, and employment on the other side. In this sense, our model highlights a mechanism that has been largely neglected so far. Our specification differs from much of the previous literature that has assumed strong non-homotheticities in the subsistence ("elementary") good. Adopting a similar assumption here would reinforce our results. Due to such non-homotheticities, any rise in formal-sector incomes (through an increase in $a$ and/or a decrease in $F$ ) would

\footnotetext{
${ }^{17}$ Note that the properties of a quadratic subutility function are quite different from those of the standard DixitStiglitz formulation. In that case, $v^{\prime}(0)=\infty$, so even the poorest consumers purchase all goods that are supplied (albeit in tiny amounts), and the elasticity of demand $\eta(c)$ is the same for all consumers, i.e., it does not depend on consumed quantities.

${ }^{18}$ Foellmi and Zweimüller (2004) analyze the impact of inequality on mark-ups in the context of a symmetric equilibrium. It turns out that the curvature of the coefficient of absolute risk aversion, $-v^{\prime \prime}(c) / v^{\prime}(c)$, determines whether higher inequality in the size distribution of income increases or decreases the mark-up.
} 
lead to an even stronger shift of demand towards differentiated products and away from subsistence.

Technology.-We assumed that there is no substitution possible between skilled and unskilled workers in the formal sector. However, the result that purchasing power effects may dominate cost effects still holds true if we allow for substitution between the two types of labor. Interestingly, in the other polar case, with perfect substitution, the same effects are present: as long as unskilled labor is cheaper (per efficiency unit) than skilled labor, only the unskilled are employed in the formal sector. A small increase in unskilled wages will not change this allocation and will leave the number of firms unchanged, but it may increase employment due to the purchasing power effect (for an analysis of this case with a more general production function, see Foellmi and Zweimüller 2006b).

For intermediate degrees of the elasticity of substitution the cost effect of higher low-skilled wages presumably becomes stronger. Compared to the Leontief case, labor demand falls more strongly when marginal costs $c$ and hence wages $w(c)$ increase. Firms will replace unskilled by skilled workers so that an upward-sloping labor demand relation, while still possible, becomes less likely. ${ }^{19}$

More General Distributions. - A simplifying assumption of our analysis was that there are only two types of consumers: the rich and the poor. How would the analysis change by allowing for arbitrarily many groups? To get the intuition of how the analysis extends to many groups, consider the case of two groups of unskilled workers so there are three groups: the rich, the poor, and the middle class. A candidate for a general equilibrium would be a situation where some firms sell only to the rich, other firms sell to the rich and the middle class and a final group of firms sells to all consumers. Whether or not such an equilibrium arises depends on how different the various groups are. When the rich, the middle class, and the poor differ only slightly, a symmetric equilibrium will arise. When the rich and the middle class are very similar, there will be a situation where the poor but not the middle class are excluded from some markets. When the poor and the middle class are very similar, the poor and the middle class are excluded from the same markets, and so on. It is obvious that this line of reasoning can be extended to the general case with $x$ different groups of households. The equilibrium will be characterized by $z \leq x$ different types of firms, where $z$ is weakly smaller than $x$, reflecting the fact that the market equilibrium merges very similar groups. Furthermore, a redistribution of income from richer to poorer households has effects analogous to the redistribution discussed in the two-group economy, provided that the redistribution occurs between groups that are sufficiently different.

Regarding the labor supply, the picture would also look different. When there are many types of low-skilled workers, the labor supply curve would become smooth, generating a critical group that is indifferent between subsistence and formal-sector

\footnotetext{
${ }^{19}$ We performed simulations for a Cobb-Douglas technology in the formal sector. When the income share of the high-skilled in the formal sector is sufficiently low, the general-equilibrium demand curve is still upward sloping.
} 
work. All workers poorer than this critical group remain in subsistence, whereas all workers richer than this critical group take a job in the formal sector.

Theoretical Predictions and Empirical Evidence.-Our model has several distinctive implications about relative prices, markups, and firm sizes. One empirically testable prediction is that mark-ups are higher in more unequal economies. We are not aware of any systematic evidence on the determinants of mark-ups in developing economies. For developed economies, however, Chris Edmond and Laura Veldkamp (2009) do indeed find a positive correlation between earnings inequality and markups. Kalina Manova and Zhiwei Zhang (2009), using crosscountry data, show that firms set higher markups in richer markets. This is consistent with the prediction of our model that prices and mark-ups vary systematically with the income level of consumers. A further prediction of our model is that the size distribution of firms mirror the extent of inequality in the size distribution of endowments (such as land and human capital). Empirical evidence from developing countries suggests that the size distribution of firms is indeed very unequal and polarized in poor countries, where inequality is typically very high (Tybout 2000). (See, e.g., Leo Sleuwaegen and Micheline Goedhuys 2002, for an empirical analysis of the firm size distribution in Côte d'Ivoire, a country with extremely high inequality). While the firm-size distribution is affected by many different channels, we think it is worthwhile to explore the role of purchasing power and the size of consumer markets.

\section{Conclusions}

In this paper, we have studied the impact of income inequality on formal-sector employment in a less developed economy. Our analysis provides a theoretical explanation for the old argument that a more egalitarian distribution of income, by generating purchasing power for the lower classes, may enhance employment opportunities and help to overcome the underemployment problem. In contrast to the previous literature, we emphasize a demand channel through which income inequality affects the price-setting behavior and employment decisions of monopolistic firms. We study a dual-economy framework where consumers have non-homothetic preferences over the goods produced in the modern sector. Combining these preferences with the standard monopolistic competition framework allows us to highlight a potentially important channel through which inequality may affect aggregate employment. In particular, we have shown that in an unequal society, there are "exclusive firms," that set high prices (and mark-ups) and sell only to the rich, and "mass producers," which set low prices and serve the entire customer base. By generating more mass production, a more egalitarian society is able to absorb a larger fraction of employment and reduce the reserve army of labor trapped in subsistence.

This adverse effect of inequality on formal-sector employment works via the changing composition of firms. Higher inequality generates increased incentives to exploit the high willingness to pay among the rich consumers, which shifts the composition of firms away from being mass producers toward being small, exclusive firms. The decrease in employment by mass producers is not fully offset by the 
higher entry and employment of exclusive producers. We have also shown that an increase in subsistence productivity boosts formal-sector wages and the employment of unskilled workers. Higher wages in the formal sector generate purchasing power effects that increase mass production. The purchasing power effect (higher employment due to more mass production) dominates the familiar cost effect (lower employment due to higher production costs). The increase in unskilled wages, while reducing the incomes of the rich, may nevertheless improve their welfare due to higher production and lower prices of goods in the formal sector.

While our analysis relied on the assumption of non-homothetic preferences, the way in which such preferences are adopted in the present paper differs substantially from most previous papers that have relied on an explanation based on non-homothetic preferences. The specification of non-homothetic preferences in the existing literature typically relies on income elasticities below unity in the subsistence sector and income elasticities above unity in the formal sector. This is different in the present framework. Under our specification, a uniform increase in income, for example, through a joint increase in productivity $a$ and decrease in fixed costs $F$ to leave $a F$ unaffected, does not change the sectoral composition as long as relative prices remain unchanged. In contrast, non-homotheticities work entirely via the demand functions for differentiated products of the formal sector. These demand functions feature decreasing price elasticities and finite reservation prices, thus generating interesting interactions between income inequality on the one side and price, markups, and employment on the other side. In this sense, our model highlights a mechanism that has been largely neglected so far.

Our model could be extended in various directions. First, our model is static, and it may be worthwhile to extend the analysis to a dynamic context. Allowing for innovation decisions brings interesting new elements into the picture. With nonhomothetic preferences, distribution will affect the choice of whether to introduce new products or to search for more efficient production processes. A second potentially interesting extension concerns international trade. Our model is closed, and opening it up for international trade would enable the exploration of the interaction between increasing returns and economic inequality as a determinant of trade flows. Inter alia, this may provide a rationale for why terms of trade may be affected by demand considerations (such as the relative size of home markets) and income distribution. A final interesting extension concerns the medium-run equilibrium. While our analysis provides a much richer framework to incorporate the price-setting behavior of firms, wage-setting behavior was treated as a black-box. Incorporating wage-setting using more detailed assumptions on labor-market institutions would be potentially interesting for studying the interaction of product market and labor regulations for unemployment in the medium run.

\section{Mathematical ApPendix}

\section{A. PROOF OF PROPOSITION 1:}

In a symmetric equilibrium, we must have $\Pi^{M} \geq \Pi^{E}$ so that no firm has an incentive to deviate and adopt the exclusion strategy. In asymmetric equilibria, mass consumption producers and exclusive producers must earn the same profit $\Pi^{M}=\Pi^{E}$. 
A situation where $\Pi^{M}<\Pi^{E}$ cannot be an equilibrium: no firm would sell to the poor, which would leave them with idle purchasing power and very high willingness to pay for some goods. Let us now find a condition under which no firm has an incentive to sell exclusively to the rich. For a given wage level $w$, we evaluate equilibrium profits in a symmetric equilibrium, and we denote these profits by $\tilde{\Pi}^{E}$ and $\tilde{\Pi}^{M}$. To derive an expression for $\tilde{\Pi}^{E}$ note that $\lambda_{R}=s-x_{R}^{M}, p^{M}$ is the numeraire. To determine $x_{R}^{M}$, we use the budget constraint of the rich in a symmetric equilibrium: $N x_{R}^{M}=\Pi^{M} H / F$. Hence, $x_{R}^{M}=s[1-c]^{2} /[2-c]$. We get the critical profits levels $\tilde{\Pi}^{E}$ and $\tilde{\Pi}^{M}$ in terms of $c$ and exogenous parameters

$$
\tilde{\Pi}^{E}=\frac{s}{4} \frac{[(1-\beta)(2-c)+c(1-c)]^{2}(1-c)^{2}}{\left[(1-\beta)(2-c)-(1-c)^{2}\right](2-c)} \text {, and } \tilde{\Pi}^{M}=s \frac{(1-c)^{2}}{2-c} \text {. }
$$

The symmetric outcome is an equilibrium if, starting from a situation where all firms charge a price that attracts the whole customer base, no single firm has an incentive to deviate and adopt the exclusive good strategy. In other words, the inequality $\tilde{\Pi}^{E}<\tilde{\Pi}_{M}$ must hold strictly. Using equations (20), we get

$$
\frac{\tilde{\Pi}^{E}}{\tilde{\Pi}^{M}}=\frac{1}{4} \frac{[(1-\beta)(2-c)+c(1-c)]^{2}}{(1-\beta)(2-c)-(1-c)^{2}}<1 .
$$

The left-hand side of (21) is decreasing in $c$. We inspect the derivative

$$
\begin{aligned}
& \frac{\partial}{\partial c} \frac{1}{4} \frac{[(1-\beta)(2-c)+c(1-c)]^{2}}{(1-\beta)(2-c)-(1-c)^{2}} \\
= & \frac{1}{4} \frac{\left[(1-\beta)(2-c)-(1-c)^{2}+(1-c)\right]\left[-2(1-c)^{3}+2 \beta(1-\beta)-[6-\beta(5+\beta)] c+3(1-\beta) c^{2}\right]}{\left[(1-\beta)(2-c)-(1-c)^{2}\right]^{2}} \\
< & 0 .
\end{aligned}
$$

Recall that $(1-\beta)(2-c)>(1-c)^{2}$, this implies the second term in brackets of the nominator is increasing in $\beta$. At $\beta=1$, the second term in brackets equals $-2(1-c)^{3}<0$, which confirms the negative sign of the derivative. Further, $\operatorname{LHS}(c=1)=(1-\beta) / 4<1$ and $\operatorname{LHS}(c=0)=(1-\beta)^{2} /(1-2 \beta)>1$. Hence, there exists a unique level of marginal costs $\hat{c}$ with $\operatorname{LHS}(\hat{c})=1$. If the equilibrium marginal cost $c_{s y m}$ is larger than $\hat{c}$, a symmetric equilibrium exists. To derive a condition for existence of the symmetric equilibrium in terms of the parameters, we insert the equilibrium marginal costs into (21). From $(19) c_{\text {sym }}=[H-(2 \zeta+1)$ $\times((1-\alpha) / \alpha) \ell L] /[H-(\zeta+1)((1-\alpha) / \alpha) \ell L]$, we get a sufficient condition for the existence of a symmetric equilibrium

$$
\frac{1}{4} \frac{[(1-\beta)(2-\xi)+\xi(1-\xi)]^{2}}{(1-\beta)(2-\xi)-(1-\xi)^{2}}<1 \text { with } \xi \equiv \frac{H-(2 \zeta+1) \frac{1-\alpha}{\alpha} \ell L}{H-(\zeta+1) \frac{1-\alpha}{\alpha} \ell L}
$$




\section{B. PROOF OF LEMMA 2:}

We must show that $\partial \Psi(c, \ell) / \partial \beta<0$.

$$
\frac{\partial \Psi}{\partial \beta}=\frac{N}{a(1-\alpha)}\left[\frac{\partial n}{\partial \beta}\left(X^{M}-X^{E}\right)+\frac{\partial X^{E}}{\partial \beta}\right] .
$$

The expression in square brackets is negative if $\partial x_{P}^{M} / \partial \beta<0$ (which implies $\partial n / \partial \beta<0$, see equation (14)) and $\partial X^{E} / \partial \beta<0$.

To show that $\partial n / \partial \beta<0 \equiv(N(\ell) / a(1-\alpha))\left[n(c, \ell) X^{M}(c)+(1-n(c, \ell))\right.$ $\left.\times X^{E}(c)\right]-\ell L$

$$
\frac{\partial x_{P}^{M}(\beta)}{\partial \beta}=\frac{s}{\beta^{2}} \frac{2}{2 p^{E}-c}\left[\frac{p^{E}-1}{2-c}-\frac{\beta(1-\beta)}{2 p^{E}-c} \frac{\partial p^{E}}{\partial \beta}\right] .
$$

Total differentiation of (9) gives the partial derivative of $p^{E}$ with respect to $\beta$,

$$
\begin{aligned}
\frac{\partial p^{E}}{\partial \beta} & =\frac{1}{2} \frac{1}{1-\beta} \frac{p^{E}-c}{p^{E}}\left(2 p^{E}-c\right) \\
\frac{\partial x_{P}^{M}(\beta)}{\partial \beta} & =\frac{s}{\beta^{2}} \frac{2}{2 p^{E}-c}\left[\frac{p^{E}-1}{2-c}-\frac{\beta}{2} \frac{p^{E}-c}{p^{E}}\right] \\
& =\frac{s}{\beta^{2}} \frac{2\left(p^{E}-1\right) p^{E}-\beta\left(p^{E}-c\right)(2-c)}{\left(2 p^{E}-c\right)(2-c)} .
\end{aligned}
$$

The nominator $\aleph$ is increasing in $\beta$. To show this, we calculate its derivative

$$
\begin{aligned}
\frac{\partial \aleph}{\partial \beta} & =\frac{p^{E}-c}{1-\beta} \frac{2\left(2 p^{E}-c\right)-\left(2 p^{E}-c\right)\left(1+\beta \frac{2-c}{c}\right) / p^{E}-(1-\beta)(2-c)}{\left(2 p^{E}-c\right)(2-c)} \\
& =\frac{p^{E}-c}{1-\beta} \frac{2 p^{E}-c+2\left(p^{E}-1\right)-\left(2 p^{E}-c\right) / p^{E}+\beta c(2-c) /\left(2 p^{E}\right)}{\left(2 p^{E}-c\right)(2-c)}>0 .
\end{aligned}
$$

This implies that for all $\aleph(\beta)=2\left(p^{E}-1\right) p^{E}-\beta\left(p^{E}-c\right)(2-c)>\aleph(0)=0$. We conclude that $\partial x_{P}^{M}(\beta) / \partial \beta>0$ for $\beta>0$.

Finally, we show that $\partial X^{E} / \partial \beta<0$. Note that $X^{E}=(1-\beta) x_{R}^{E}=(1-\beta)$ $\times s\left[\left(p^{E}-c\right) /\left(2 p^{E}-c\right)\right]$

$$
\begin{aligned}
\frac{1}{s} \frac{\partial X^{E}}{\partial \beta} & =-\frac{p^{E}-c}{2 p^{E}-c}+\frac{c(1-\beta)}{\left(2 p^{E}-c\right)^{2}} \frac{\partial p^{E}}{\partial \beta} \\
& =-\frac{p^{E}-c}{2 p^{E}-c}+\frac{1}{2} \frac{c}{2 p^{E}-c} \frac{p^{E}-c}{p^{E}} \\
& =-\frac{1}{2} \frac{p^{E}-c}{p^{E}}<0 .
\end{aligned}
$$




\section{MORE GENERAL PREFERENCES}

We show the following: With HARA preferences and $v^{\prime}(0)$ finite, more inequality raises markups in a unique asymmetric equilibrium.

When preferences are HARA, $v(\cdot)$ is given by $v^{\prime}(c)=(c / \sigma+s)^{-\sigma}$ with $s>0$ and $\sigma \in \Re$. Note that we get for $\sigma=-1$ the quadratic utility function used above. The assumption of $s>0$ guarantees that $v^{\prime}(0)$ is finite. The elasticity of substitution equals $c /(c / \sigma+s)$ which is monotonically increasing in $c$.

To make things as simple as possible, we will consider an asymmetric equilibrium with full employment in the formal sector. The generalized Stone-Geary with $\sigma<1$ and negative consumption requirement satisfies this property, for example.

Denote by $x^{E}$ and $x^{M}$ consumption of mass and exclusive goods, respectively. Instead of the price of mass consumption goods, we now normalize marginal costs $w / G=1$ and get the following Lerner indices

$$
\frac{p^{E}-1}{p^{E}}=\frac{x^{E}(1-\beta)}{x^{E}(1-\beta) / \sigma+s}
$$

and

$$
\frac{p^{M}-1}{p^{M}}=\frac{x^{M}}{x^{M} / \sigma+s}
$$

The profit arbitrage condition is given by

$$
\left(p^{M}-1\right) x^{M}=\left(p^{E}-1\right) x^{E} .
$$

For simplicity, we consider a full employment equilibrium, hence the aggregate resource constraint reads

$$
n x^{M}+(1-n) x^{E}=1
$$

Now, consider a rise in inequality. In a unique equilibrium, more inequality leads to more exclusion, i.e., a decrease in $n$. Assume to the contrary that $p^{E}$ falls. By (C1), $x^{E}$ must also decrease. (C3) then implies that $\left(p^{M}-1\right) x^{M}$ falls. From (C2) we know, however, that $p^{M}$ and $x^{M}$ are positively related. Therefore, both $p^{M}$ and $x^{M}$ must decrease. Taken together $n x^{M}+(1-n) x^{E}$ must fall (recall that $\left.x^{M}>x^{E}\right)$. But this contradicts the aggregate resource constraint (C4). Hence, we conclude $p^{E}$

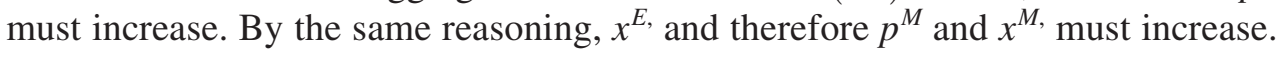
Thus, markups rise.

\section{REFERENCES}

Blanchard, Olivier J. 1997. “The Medium Run.” Brookings Papers on Economic Activity, (2): 89-141. Bulow, Jeremy I., and Lawrence H. Summers. 1986. "A Theory of Dual Labor Markets with Application to Industrial Policy, Discrimination, and Keynesian Unemployment." Journal of Labor Economics, 4(3): 376-414. 
Chong, Alberto, and Mark Gradstein. 2007. "Inequality and Informality." Journal of Public Economics, 91(1-2): 159-79.

Chou, Chien-Fu, and Gabriel Talmain. 1996. "Redistribution and Growth: Pareto Improvements." Journal of Economic Growth, 1(4): 505-23.

Dasgupta, Partha, and Debraj Ray. 1987. "Inequality as a Determinant of Malnutrition and Unemployment: Policy.” Economic Journal, 97(385): 177-88.

d'Aspremont, Claude, Rodolphe Dos Santos Ferreira, and Louis-André Gérard-Varet. 1990. “On Monopolistic Competition and Involuntary Unemployment." Quarterly Journal of Economics, 105(4): 895-919.

Dehez, Pierre. 1985. "Monopolistic Equilibrium and Involuntary Unemployment." Journal of Economic Theory, 36(1): 160-65.

de Soto, Hernando. 1989. The Other Path: The Invisible Revolution in the Third World. New York: Harper \& Row.

Dixit, Avinash K., and Joseph E. Stiglitz. 1977. "Monopolistic Competition and Optimum Product Diversity." American Economic Review, 67(3): 297-308.

Djankov, Simeon, Caralee McLiesh, and Andrei Shleifer. 2007. "Private Credit in 129 Countries." Journal of Financial Economics, 84(2): 299-329.

Djankov, Simeon, Rafael La Porta, Florencio Lopez-de Silanes, and Andrei Shleifer. 2002. "The Regulation of Entry." Quarterly Journal of Economics, 117(1): 1-37.

Edmond, Chris, and Laura Veldkamp. 2009. "Income Dispersion and Counter-cyclical Markups." Journal of Monetary Economics, 56(6): 791-804.

Falkinger, Josef. 1994. "An Engelian Model of Growth and Innovation with Hierarchic Consumer Demand and Unequal Incomes.” Ricerche Economiche, 48(2): 123-39.

Flam, Harry, and Elhanan Helpman. 1987. "Vertical Product Differentiation and North-South Trade." American Economic Review, 77(5): 810-22.

Foellmi, Reto, and Manuel Oechslin. 2007. "Who Gains from Non-collusive Corruption?" Journal of Development Economics, 82(1): 95-119.

Foellmi, Reto, and Josef Zweimüller. 2004. "Inequality, Market Power, and Product Diversity." Economics Letters, 82(1): 139-45.

Foellmi, Reto, and Josef Zweimüller. 2006a. "Income Distribution and Demand-Induced Innovations." Review of Economic Studies, 73(4): 941-60.

Foellmi, Reto, and Josef Zweimüller. 2006b. "Mass Consumption: Exclusion and Unemployment." University of Zurich Institute for Empirical Research in Economics Working Paper 296. http:// www.iew.uzh.ch/wp/iewwp296.pdf.

Galor, Oded, and Omer Moav. 2004. "From Physical to Human Capital Accumulation: Inequality and the Process of Development.” Review of Economic Studies, 71(4): 1001-26.

Hart, Oliver. 1982. "A Model of Imperfect Competition with Keynesian Features.” Quarterly Journal of Economics, 97(1): 109-38.

Lewbel, Arthur. 2006. "ENGEL CURVES Entry for The New Palgrave Dictionary of Economics, 2nd edition.” http://www2.bc.edu/ lewbel/palengel.pdf.

Li, Chol-Won. 1996. "Inequality and Growth: A Schumpeterian Perspective.” Unpublished.

Manova, Kalina, and Zhiwei Zhang. 2009. "Quality Heterogeneity across Firms and Export Destinations." http://www.stanford.edu/ manova/prices.pdf.

Matsuyama, Kiminori. 2000. "A Ricardian Model with a Continuum of Goods under Nonhomothetic Preferences: Demand Complementarities, Income Distribution, and North-South Trade." Journal of Political Economy, 108(6): 1093-1120.

Matsuyama, Kiminori. 2002. "The Rise of Mass Consumption Societies.” Journal of Political Economy, 110(5): 1035-70.

Mitra, Devashish, and Vitor Trindade. 2005. "Inequality and Trade." Canadian Journal of Economics, 38(4): 1253-71.

Murphy, Kevin M., Andrei Shleifer, and Robert W. Vishny. 1989. "Income Distribution, Market Size, and Industrialization.” Quarterly Journal of Economics, 104(3): 537-64.

Rosser, J. Barkley, Marina V. Rosser, and Ehsan Ahmed. 2000. "Income Inequality and the Informal Economy in Transition Economies.” Journal of Comparative Economics, 28(1): 156-71.

Saint-Paul, Gilles. 2006. "Distribution and Growth in an Economy with Limited Needs: Variable Markups and 'The End of Work'.” Economic Journal, 116(511): 382-407.

Silvestre, Joaquim. 1990. "There May Be Unemployment When the Labour Market Is Competitive and the Output Market Is Not.” Economic Journal, 100(402): 899-913.

Silvestre, Joaquim. 1993. "The Market-Power Foundations of Macroeconomic Policy." Journal of Economic Literature, 31(1): 105-41. 
Sleuwaegen, Leo, and Micheline Goedhuys. 2002. "Growth of Firms in Developing Countries, Evidence from Côte d'Ivoire.” Journal of Development Economics, 68(1): 117-35.

Solow, Robert M. 2000. "Toward a Macroeconomics of the Medium Run." Journal of Economic Perspectives, 14(1): 151-58.

Tybout, James R. 2000. "Manufacturing Firms in Developing Countries: How Well Do They Do, and Why?" Journal of Economic Literature, 38(1): 11-44.

Winkelried, Diego. 2005. "Income Distribution and the Size of the Informal Sector." http://ideas.repec. org/p/wpa/wuwpdc/0512005.html. 